\title{
Acessibilidade e deficiência física: identificação de barreiras arquitetônicas em áreas internas de hospitais de Sobral, Ceará*
}

\author{
ACCESSIBILITY AND PHYSICAL DEFICIENCY: IDENTIFYING ARCHITECTURAL \\ BARRIERS IN INTERNAL AREAS OF HOSPITALS IN SOBRAL, CEARÁ
}

\section{ACCESIBILIDAD Y DEFICIENCIA FÍSICA: IDENTIFICACIÓN DE BARRERAS ARQUITECTÓNICAS EN ÁREAS INTERNAS DE HOSPITALES DE SOBRAL, CEARÁ}

\section{Lorita Marlena Freitag Pagliuca', Antônia Eliana de Araújo Aragão", Paulo César AlmeidallI}

\section{RESUMO}

Pesquisa sobre as barreiras físicas encontradas pelos portadores de deficiência em áreas internas de quatro hospitais de Sobral-Ceará. Estudo quantitativo no qual a coleta de dados foi realizada por cheque-lista baseada na NBR 9050 da Associação Brasileira de Normas Técnicas (ABNT), em maio de 2004. A análise constatou o seguinte: presença de rampas de acesso (100\%); escadaria sem corrimão (50\%); portas possuem largura ideal (100\%); as de vai-e-vem não têm visor (100\%); áreas internas de circulação possuem obstáculos (100\%); piso das rampas não antiderrapantes $(100 \%)$; rampas e escadas com corrimão (50\%), mas fora do padrão legal. Um hospital é térreo, os outros possuem treze escadas internas; balcões $(80 \%)$ e assentos públicos (33\%) atendem à legislação; bebedouros e telefones não são acessíveis (97\%). Concluiu-se que há barreiras físicas e que a legislação está sendo desrespeitada.

\section{DESCRITORES}

Pessoas portadoras de deficiência.

Acesso aos serviços de saúde. Hospitais.

\begin{abstract}
The objective of this research was to identify architectural barriers for the physically handicapped in the internal areas of four hospitals in the city of Sobral, in the State of Ceará. This is a quantitative study for which data collection was carried out in May of 2004 using a checklist based on the NBR 9050, of the Brazilian Technical Standards Organization (ABNT). The analysis identified the presence of access ramps (100\%); staircases without banisters (50\%); doors with ideal width (100\%); swinging doors with no windows $(100 \%)$; internal circulation areas with obstacles $(100 \%)$; ramps with no antiskid floors (100\%); ramps and staircases with banisters $(50 \%)$, but out of legal standards. One hospital was built entirely on the ground floor, but the others have thirteen internal staircases; $80 \%$ of the counters and $33 \%$ of the seats for the public comply with legal standards; $97 \%$ of the drinking fountains and telephones are not accessible. The conclusion is that there are physical barriers in these institutions and that the legislation is not being complied with.
\end{abstract}

\section{KEY WORDS}

Disabled persons.

Health services accessibility. Hospitals.

\section{RESUMEN}

Pesquisa sobre las barreras físicas encontradas por los portadores de deficiencia en áreas internas de cuatro hospitales de Sobral - Ceará. Estudio cuantitativo en el cual la colecta de datos fue realizada por cheque-lista basada en la NBR 9050 de la Asociación Brasileña de Normas Técnicas (ABNT), en mayo de 2004. La análisis constató lo siguiente: presencia de rampas de acceso (100\%); escaleras sin pasamano (50\%); puertas poseen largura ideal (100\%); las de ida y vuelta no tiene visor (100\%); áreas internas de circulación poseen obstáculos (100\%); suelo que no derrapan (100\%) ;rampas y escaleras con pasamano $(50 \%)$, pero fuera del padrón legal. Un hospital es plano, los otros poseen trece escaleras internas; balcones $(80 \%)$ y asientos públicos (33\%) atienden a la legislación; lugares para beber agua y teléfono no son accesibles (97\%). Se concluye que hay barreras físicas y que la legislación está siendo desacata.

DESCRIPTORES

Personas con discapacidad. Accesibilidad a los servicios de salud.

Hospitales.
Extraído da dissertação "Acessibilidade da pessoa portadora de deficiência física aos serviços hospitalares: avaliação das barreiras arquitetônicas", Programa de Pós - Graduação em Enfermagem, Universidade Federal do Ceará, 2004.

I Enfermeira. Doutora em Enfermagem. Professora Titular do Departamento de Enfermagem, Universidade Federal do Ceará (UFC), Fortaleza, CE, Brasil. Coordenadora do Projeto Acessibilidade da Pessoa Portadora de Deficiência Física e ou Sensorial aos Serviços de Saúde: Estudo das Condições Físicas e de Comunicação, Ministério da Saúde/FUNCAP. pagliuca@ufc.br

II Enfermeira. Mestre em Enfermagem Clínico-Cirúrgica. Ex-bolsista FUNCAP aragaoantonia@ ig.com.br

III Doutor em Estatís tica. Professor da Universidade Federal do Ceará (UFC), Fortaleza, CE, Brasil. 


\section{INTRODUÇÃO}

Todas as pessoas, entre as quais se incluem as que possuem algum tipo de deficiência, têm direito ao acesso à educação, à saúde, ao lazer e ao trabalho. Essas áreas contribuem para a inserção social, desenvolvimento de uma vida saudável e de uma sociedade inclusiva.

As pessoas com deficiência física para exercerem esses direitos e fortalecerem sua participação como cidadãos, há necessidade de se atingir alguns objetivos, como o direito a acessibilidade em edificações de uso público. Assim, a conquista por espaços livres de barreiras arquitetônicas implica a possibilidade e a condição de alcance para que portadores de deficiência utilizem com segurança e autonomia as edificações, mobiliários, os equipamentos urbanos, os transportes e meios de comunicação ${ }^{(1)}$.

Apesar das dificuldades há conquistas, a exemplo da Lei $\mathrm{n}^{\circ} 7.853 / 89$, que promove integração social e define punições quando se negar emprego a estas pessoas, deixar de prestar assistência médico-hospitalar, ou de cumprir ordem judicial e mesmo retardar ou frustrar esta ordem.

A despeito da legislação, ainda se percebe pouca preocupação com a acessibilidade destas pessoas aos ambientes hospitalares. Para avaliação das condições de acessibilidade hospitalar são considerados o seu contexto e missão; o compromisso com a comunidade; os aspectos políticos, sociais e financeiros. Em relação ao hospital, o administrador deve focalizar o contínuo aperfeiçoamento do trabalho em equipe, participativo, com raciocínio estatístico e práticas humanizadas ${ }^{(2)}$. Desta forma, onde existem barreiras arquitetônicas aos usuários, a qualidade está comprometida.

Embora pessoas portadoras de deficiência física estejam sempre presentes na comunidade, na assistência hospitalar e na docência, isto não garante sensibilização e reflexão dos profissionais da saúde sobre as dificuldades encontradas por elas no dia-a-dia. Na reflexão sobre as necessidades destas pessoas dentro dos hospitais, particularmente quando em situação de doença, percebeu-se as barreiras arquitetônicas que comprometem o acesso e a mobilidade dos portadores de deficiência física quando hospitalizados.

Desse modo, o projeto de pesquisa Acessibilidade da Pessoa Portadora de Deficiência Física elou Sensorial aos Serviços de Saúde: Estudo das Condições Físicas e de Comunicação forneceu informações necessárias para despertar a inquietação de pesquisar sobre as barreiras físicas existentes dentro dos hospitais da cidade de Sobral. Conforme se acredita, os resultados do estudo podem contribuir para redução destas barreiras arquitetônicas e propiciar uma nova abordagem do processo assistencial na busca da promoção da saúde e qualidade de vida das pessoas portadoras de deficiência.

Ante o exposto, e por reconhecer os direitos legítimos e legais de acessibilidade e integração social das pessoas portadoras de deficiência física, este estudo teve como objetivo identificar as barreiras arquitetônicas para portadores de deficiência física nas áreas internas dos hospitais da cidade de Sobral, no Estado do Ceará.

Como amparo legal deste estudo, menciona-se a Lei $\mathrm{n}^{\circ}$ 10.098 de 19 de dezembro de $2000^{3}$, que estabelece normas gerais e critérios básicos para a promoção da acessibilidade por pessoas portadoras de deficiência ou com mobilidade reduzida. As normas foram estabelecidas para assegurar a integração social por meio do exercício dos direitos individuais e sociais, embasadas no respeito à dignidade e na justiça social, no intuito de possibilitar às pessoas com limitação física acesso à educação, à saúde, ao trabalho, ao lazer, à previdência social, além de amparo à infância e à maternidade. Assim, a lei contempla basicamente todas as áreas indispensáveis à inclusão social das pessoas com limitação. Portanto, visa garantir ações institu-cionais voltadas a suprimir discriminações e preconceitos de qualquer espécie.

$\mathrm{Na}$ área da saúde a legislação garante acesso à promoção da saúde, visita domiciliar, atendimento médico diferenciado e programas de saúde específicos ${ }^{(4)}$, de tal modo que estas pessoas tenham acesso à rede de serviços especializados em reabilitação e habilitação, bem como a tratamento adequado nos estabelecimentos de saúde público e privado. Consoante estabelecido pela mencionada lei, configura-se crime, punível com reclusão de um a quatro anos e multa, recusar, retardar ou dificultar de alguma forma o acesso da pessoa portadora de deficiência física ao serviço de saúde, ou negligenciar assistência médico-hospitalar e ambulatorial, quando possível, a essas pessoas.

\section{MÉTODO}

Trata-se de um estudo quantitativo centrado em fatos objetivamente detectados e observáveis, seja em sua produção, seja em seu desenvolvimento ${ }^{(5)}$. Segundo definido, o estudo constou do mapeamento das condições arquitetônicas de acesso do deficiente físico aos hospitais de Sobral, situada na região Norte do Estado do Ceará, a $240 \mathrm{~km}$ de Fortaleza. A cidade possui a quinta maior população do Estado, e está localizada no sertão. Tem clima quente, conta com uma área territorial de aproximadamente $1.700 \mathrm{~km}^{2}$. No setor saúde, constitui referência para a Zona Norte do Estado, e é considerada um Pólo Assistencial da Região ${ }^{(6)}$. 
O universo do estudo foi formado pelos hospitais da cidade de Sobral, assim classificados: hospital geral de porte IV, com 313 leitos, de caráter filantrópico, que mantêm convênio com o Sistema Único de Saúde (SUS), instituições diversas e particulares; hospital geral, de porte III, com 142 leitos, de caráter particular, conveniado com o SUS e com outras instituições e particulares; hospital especializado, de porte II, com 55 leitos, de caráter filantrópico, conveniado com o SUS e com outras instituições e particulares; hospital geral, de porte I, que atende pacientes conveniados com a UNIMED, com 35 leitos, seis dos quais destinados a atendimento de parturientes encaminhadas pelo SUS ${ }^{(7)}$. Estes hospitais foram denominados $1,2,3 \mathrm{e} 4^{(8)}$.

A coleta de dados da pesquisa foi realizada no mês de maio de 2004, exclusivamente por uma das autoras do trabalho, enfermeira, previamente treinada nos procedimentos de coleta. O instrumento foi adaptado de outro, utilizado em projeto de pesquisa que apoiou este estudo ${ }^{(9)}$, excluídos os itens referentes a outras deficiências não abordadas neste momento. Utilizou-se um formulário elaborado a partir da NBR 9050 da Associação Brasileira de Normas Técnicas $(\mathrm{ABNT})^{(10)}$, discriminando as condições ideais de acesso estabelecidas na lei para permitir a mobilidade das pessoas portadoras de deficiência física nos hospitais selecionados.

O instrumento constou de dados de identificação de cada instituição; dados referentes às condições de acesso da pessoa com deficiência física às instituições hospitalares, no qual se abordou a via pública, o acesso ao prédio e seu interior, assim como da circulação vertical; acesso por rampas, escadas e elevadores; localização e espaços como salas e auditórios; características dos mobiliários presentes nas unidades pesquisadas. Observou-se também a presença do símbolo internacional de acesso. Além disso, constou de itens sobre as instalações sanitárias quanto à área de transferência, à bacia sanitária, aos lavatórios, aos mictórios e aos chuveiros.

Como exposto a seguir, os dados foram apresentados em forma de tabelas, após agrupamento em categorias do tipo estruturas arquitetônicas internas, compreendendo escadas e rampas, corrimão da rampa, móveis e equipamentos. A análise optou pela apresentação da frequiência de ocorrências que dificultam a mobilidade da pessoa portadora de deficiência física. Todavia as unidades de centro cirúrgico, sala de recuperação pós - anestésica, unidade neonatal e unidade de terapia intensiva não fizeram parte do estudo, pois o acesso a estes locais é restrito e, quando há necessidade de atendimento ou tratamentos específicos, são obedecidos protocolos de cada serviço.

Conforme recomendado, a investigação respeitou os princípios básicos da bioética postulados na Resolução 196/ 96 do Conselho Nacional de Saúde, quais sejam: autonomia, beneficência, não-maleficência, justiça e equidade ${ }^{(11)}$. Por fazer parte do projeto de pesquisa Acessibilidade da Pessoa Portadora de Deficiência Física e ou Sensorial aos Serviços de Saúde: Estudo das Condições Físicas e de Comunica$c ̧ \tilde{a} o^{(9)}$, possibilitou a coleta realizada com vistas a alimentar o banco de dados do projeto e do próprio estudo. Referido projeto foi submetido à apreciação do Comitê de Ética em Pesquisa do Complexo Hospitalar da Universidade Federal do Ceará (COMEPE), que o aprovou (Protocolo n. 124/02).

No campo de pesquisa, solicitou-se autorização escrita ao presidente da Comissão Científica do Hospital 1 e aos diretores administrativos dos demais hospitais. A coleta dos dados foi precedida de um comunicado às diretoras de enfermagem e às enfermeiras responsáveis pelas unidades $\mathrm{e}$ serviços envolvidos na pesquisa.

\section{APRESENTAÇÃO DOS RESULTADOS}

Como já ressaltado, a amostra deste estudo foi composta pelos quatro hospitais da cidade de Sobral, interior do Ceará. Destes hospitais, um é conveniado pela UNIMED, com atendimento restrito para clientela do SUS. Um é particular, credenciado pelo SUS, e mantém outros convênios, atendendo, inclusive, pacientes particulares. E dois são filantrópicos, também credenciados pelo SUS e mantêm outros convênios, atendendo, ainda, pacientes particulares ${ }^{(12)}$.

Foram avaliadas as condições tanto de acesso ao interior dos prédios, como das facilidades para a mobilidade no seu interior e os equipamentos e mobiliários de uso coletivo bem como sua disponibilidade para pessoas deficientes físicas. Por motivos didáticos, os dados são apresentados em tabelas onde constam itens comuns aos quatro hospitais. Deve-se lembrar, porém, que um dos hospitais é térreo. Quanto à situação do mobiliário constante das unidades de cada hospital, foram considerados os serviços selecionados para o estudo, excluídos aqueles de circulação restrita.

A Tabela 1 apresenta as condições de acesso ao interior do prédio, destacando escadas, rampas, áreas de circulação, tipos de portas e pisos. Como evidenciado, o acesso por rampa está disponibilizado somente em três hospitais avaliados por ser desnecessário no hospital térreo. Assim este item do estudo contempla três hospitais.

De acordo com tabela, o acesso se dá por escadaria sem corrimão (2); por rampa de acesso (3); as áreas de circulação possuem portas com larguras de 0,8 metros (4); as portas de vai-e-vem não são dotadas de visor (4); as portas de correr não têm trilhos rebaixados (3); os pisos não possuem superfície regular, estável, firme e antiderrapante (4); as áreas de circulação coletiva não obedecem à medida mínima de 1,20 metros de largura e não estão livres de obstáculos (4). 
Tabela 1 - Distribuição do número de hospitais segundo o acesso ao interior do prédio - Sobral - CE, maio - 2004

\begin{tabular}{l|c|c}
\hline \multicolumn{1}{c}{ SITUAÇÃO } & \multicolumn{2}{c}{ EXISTÊNCIA } \\
\cline { 2 - 3 } & SIM & NÃO \\
\hline Por escadaria sem corrimão & 2 & 2 \\
Por rampa de acesso para portador de deficiência física & 3 & 1 \\
Áreas de circulação possuem portas com largura livre de 0,8m & 4 & - \\
Portas dos tipos vai-e-vem, dotadas de visor vertical & - & 4 \\
Portas de correr possuem trilhos rebaixados & 1 & 3 \\
Pisos possuem superfície regular, estável, firme e antiderrapante. & - & 4 \\
Áreas de circulação coletiva com no mínimo 1,20m de largura e livres de obstáculos & - & 4 \\
\hline
\end{tabular}

Segundo a Tabela 2, em dois dos hospitais em estudo o corrimão da rampa é de material rígido firmemente fixado à altura de $0,92 \mathrm{~m}$ do piso e afastado $0,4 \mathrm{~m}$ da parede. Nos demais as rampas não têm corrimão. Em apenas um hospital os corrimões estão instalados de ambos os lados das esca- das e rampas; também em dois hospitais os corrimões em ralação ao piso é de 0,92 metros e estão afastados $4 \mathrm{~cm}$ da parede (2); e em nenhum dos hospitais os corrimões se prolongam a menos de $30 \mathrm{~cm}$ das paredes.

Tabela 2 - Distribuição do número de hospitais segundo a situação do corrimão da rampa - Sobral - CE, maio - 2004

\begin{tabular}{|c|c|c|}
\hline \multirow{2}{*}{ SITUAÇÃO } & \multicolumn{2}{|c|}{ EXISTÊNCIA } \\
\hline & SIM & NÃO \\
\hline O corrimão da rampa é de material rígido & 2 & 2 \\
\hline Firmemente fixado & 2 & 2 \\
\hline Instalado de ambos os lados da escada ou da rampa & 1 & 3 \\
\hline A altura é de $0,92 \mathrm{~m}$ do piso & 2 & 2 \\
\hline Está afastado $0,4 \mathrm{~m}$ da parede & 2 & 2 \\
\hline $\begin{array}{l}\text { Prolonga-se pelo menos } 0,30 \mathrm{~m} \text { antes do início e término da rampa, sem interferir com a área } \\
\text { de circulacão ou prejudicar a vazão }\end{array}$ & - & 4 \\
\hline
\end{tabular}

A Tabela 3 trata do acesso interno por escadas fixas que interligam as unidades dos três hospitais onde há escadas internas. Como ressaltado, um dos hospitais não contempla este item da pesquisa por ser constituído de um único pavimento.

Segundo aponta o estudo, nos três hospitais existem treze escadas de acesso interno. Em todas elas os degraus possuem piso de no mínimo $0,28 \mathrm{~m}$ e de $0,32 \mathrm{~m}$ no máximo, e espelho de $0,16 \mathrm{~m}$ no mínimo e de $0,18 \mathrm{~m}$ no máximo. Seis escadas possuem corrimão de material rígido, firmemente fixado, instalado de ambos os lados, afastado $0,4 \mathrm{~m}$ da parede e localizado a $0,92 \mathrm{~m}$ do piso. No Hospital 1, existe corrimão de material rígido e firmemente fixado em apenas quatro das dez escadas. No Hospital 3, há corrimão de ambos os lados em uma das escadas e na outra ele localiza-se unilateralmente. Quanto ao Hospital 2, a escada não possui corrimão de material rígido e firmemente fixado em nenhum dos lados. Existe apenas uma grade lateral.

Tabela 3 - Distribuição do número de escadas internas segundo a situação de acesso - Sobral - CE, maio - 2004

\begin{tabular}{|c|c|c|c|c|}
\hline \multirow{3}{*}{ SITUAÇÃO } & \multicolumn{4}{|c|}{ EXISTÊNCIA } \\
\hline & \multicolumn{2}{|c|}{ SIM } & \multicolumn{2}{|c|}{ NÃO } \\
\hline & $\mathrm{n}$ & $\%$ & $\mathrm{n}$ & $\%$ \\
\hline Patamar de 1,20m quando houver mudança de direção ou desnível superior a 3,25m & 1 & $<1$ & 12 & 92 \\
\hline Degraus têm piso de no mínimo $0,28 \mathrm{~m}$ & 13 & 100 & - & - \\
\hline Degraus têm piso de no máximo 0,32 m & 13 & 100 & - & - \\
\hline Degraus têm espelho de no mínimo $0,16 \mathrm{~m}$ & 13 & 100 & - & - \\
\hline Degraus têm espelho de no máximo $0,18 \mathrm{~m}$ & 13 & 100 & - & - \\
\hline Degraus possuem piso antiderrapante & 5 & 38 & 8 & 62 \\
\hline Corrimão de material rígido & 6 & 40 & 7 & 60 \\
\hline Corrimão firmemente fixado & 6 & 40 & 7 & 60 \\
\hline Corrimão de ambos os lados da escada & 6 & 40 & 7 & 60 \\
\hline Corrimão afastado $0,4 \mathrm{~m}$ da parede & 6 & 40 & 7 & 60 \\
\hline Corrimão a $0,92 \mathrm{~m}$ do piso & 6 & 40 & 7 & 60 \\
\hline Corrimão prolongado pelo menos $0,30 \mathrm{~m}$ no início e término da escada & - & - & 13 & 100 \\
\hline
\end{tabular}


Conforme se observa na Tabela 4, nas unidades em estudo dos quatros hospitais os balcões e as mesas atendem à altura de $0,80 \mathrm{~m}$ em 32 (80\%) unidades, como preconizado pela legislação. A profundidade dos assentos e sua altura do piso não estão adequadas (67\%); os bebedouros não respeitaram a altura de 80 centímetros $(97,5 \%)$; os telefones estão instalados acima da medida de 0,80 a 1,20 metros do piso $(97,5)$; as botoeiras não estão instaladas na altura entre 0,80 e 1,20 metros do piso (95\%) e os assentos ambulatoriais com espaço frontal livre de 0,60 metros estão presentes em $33 \%$ dos locais.

Tabela 4 - Distribuição do número de setores dos hospitais segundo o mobiliário existente - Sobral -CE, maio - 2004

\begin{tabular}{|c|c|c|c|c|c|c|c|c|c|c|}
\hline \multirow{2}{*}{ ITENS } & \multicolumn{2}{|c|}{1} & \multicolumn{2}{|c|}{2} & \multicolumn{2}{|c|}{3} & \multicolumn{2}{|c|}{4} & \multicolumn{2}{|c|}{ TOTAL } \\
\hline & $\mathrm{Sim}$ & Não & $\mathrm{Sim}$ & Não & $\mathrm{Sim}$ & Não & $\mathrm{Sim}$ & Não & Sim & Não \\
\hline $\begin{array}{l}\text { Balcões e mesas têm } \\
\text { altura de } 0,80 \mathrm{~m} \text { do } \\
\text { piso }\end{array}$ & 16 & 5 & 8 & 1 & 4 & 1 & 4 & 1 & $80 \%$ & $20 \%$ \\
\hline $\begin{array}{l}\text { Assentos têm } \\
\text { profundidade de } 0,40 \mathrm{~m} \\
\text { e instalados a } 0,46 \mathrm{~m} \\
\text { do piso }\end{array}$ & 6 & 15 & 5 & 4 & 2 & 3 & - & 5 & $33 \%$ & $67 \%$ \\
\hline $\begin{array}{l}\text { Bebedouros instalados } \\
\text { a } 0,80 \mathrm{~m} \text { do piso }\end{array}$ & - & 21 & 1 & 8 & - & 5 & - & 5 & $2,5 \%$ & $97,5 \%$ \\
\hline $\begin{array}{l}\text { Telefones instalados } \\
\text { entre } 0,80 \mathrm{~m} \text { e } 1,20 \mathrm{~m} \\
\text { do piso }\end{array}$ & 1 & 20 & - & 9 & - & 5 & - & 5 & $2,5 \%$ & $97,5 \%$ \\
\hline $\begin{array}{l}\text { Botoeiras entre } 0,80 \mathrm{~m} \\
\text { e } 1,20 \mathrm{~m} \text { do piso }\end{array}$ & - & 21 & - & 9 & 2 & 3 & - & 5 & $5 \%$ & $95 \%$ \\
\hline $\begin{array}{l}\text { Assentos } \\
\text { ambulatoriais com } \\
\text { espaço frontal de } 0 \text { a } \\
0,60 \mathrm{~m}\end{array}$ & 3 & 18 & 8 & 1 & 2 & 3 & - & 5 & $33 \%$ & $67 \%$ \\
\hline
\end{tabular}

\section{DISCUSSÃO}

Independente do seu caráter, as instituições de qualquer ordem são responsáveis pela segurança dos seus usuários. Da mesma forma, os hospitais, pois onde existe vida humana há necessidade de regras e normas destinadas a definir e regulamentar, como uma forma de prevenção, a segurança e convivência entre as pessoas. Ao serviço de enfermagem cabe responder pelas ações preventivas, organizacionais e de administração de recursos para prestação de cuidados aos pacientes ${ }^{(13)}$. Nestes cuidados preventivos, estão os cuidados com as escadarias, incluindo larguras ideais dos batentes e dos espelhos, piso antiderrapante, corrimão de ambos os lados, de acordo com as normas técnicas.

Por dificultar o trânsito da equipe, a presença de obstáculos interfere também no cuidado de enfermagem, porquanto estes espaços muitas vezes são transformados em salas de espera. Existe, ainda, o aglomerado de pessoas, impedindo o livre trânsito de pacientes, de acompanhantes e da equipe, pois para cuidar exige-se ambiente adequado. Cuidado representa zelo, dedicação, responsabilidade e envol-vimento com o outro no suprimento de suas necessidades humanas básicas, como, por exemplo, a acessibilidade $^{(14)}$.

Segundo evidencia a Tabela 1, em um dos hospitais o acesso se dá por escada com corrimão, enquanto nos ou- tros, os padrões preconizados pela legislação não são atendidos. Em um dos hospitais a escada possui corrimãos unilaterais, e em seu interior, dez escadas para acesso às unidades, mas cinco são usadas eventualmente pelos pacientes. Sua maior utilização é por funcionários em serviço ou pelo público, ao se deslocar para solucionar questões relacionadas à busca de documentos, como, por exemplo, atestados de óbito, fotocópias de prontuários. Ou ainda por ocasião de encontros e reuniões científicas direcionadas a pacientes com patologias específicas, como diabetes e hipertensão, entre outras. Destas escadas, quatro possuem corrimãos fora dos padrões especificados pelas normas técnicas da ABNT e uma nem sequer os possui. Das cinco utilizadas necessariamente pelos pacientes, todas têm como proteção as paredes bilaterais. Em apenas um dos hospitais o acesso ocorre por meio de escadarias com corrimão, o que facilita a mobilização das pessoas deficientes e proporciona a segurança aos usuários em geral.

Em três dos hospitais em estudo o acesso ao interior do prédio ocorre por rampa de acesso interno e em um dos hospitais existem sete rampas. Destas, cinco têm como proteção as paredes bilaterais. Outra possui grades bilaterais e a outra, unilateral, tendo como proteção a parede do lado oposto. Uma das rampas de um dos hospitais dispõe de corrimão bilateral por toda a extensão, mas não possui curvatura e nem prolongamento no início e no final da rampa. 
Ainda conforme observado, em todos os hospitais existem portas com largura livre de $0,80 \mathrm{~m}$, favorecendo o livre trânsito de pessoas em cadeiras de rodas. Neles não foram encontradas portas do tipo vai-e-vem dotadas de visor vertical. O visor tem a finalidade de facilitar a visibilidade de pessoas ou objetos que possam estar do lado oposto; desse modo, evitam acidentes comuns, como abalroamento, atropelamento de pessoas ou objetos.

Piso com superfície regular, estável e firme foi encontrado em todos os hospitais, enquanto piso antiderrapante não foi encontrado, pois eram utilizados modelos convencionais de piso. Quanto às áreas de circulação coletiva, nenhum hospital preenche totalmente a exigência da lei, porque embora possuam a largura mínima de 1,20m determinada não estão livres de obstáculos como lixeiras, bebedouros e mobiliários.

No referente aos corrimões das rampas, não atendem aos itens de segurança. Em um dos hospitais a rampa possui corrimão unilateral no acesso ao interior do prédio. No Hospital 1 existem seis rampas internas sem corrimãos. Uma delas apresenta grades de proteção bilateral, outra se encontra livre de qualquer proteção, enquanto quatro rampas são protegidas pelas paredes das unidades. Todas possuem piso antiderrapante.

No Hospital 2, existe uma rampa interna com corrimão bilateral e duas sem corrimão. No 3, há uma rampa interna sem corrimão, cuja proteção são as paredes. A outra rampa de acesso é formada pela calçada que liga a entrada à recepção. Em um dos hospitais os corrimãos estão instalados de ambos os lados da rampa, mas não se prolongam por no mínimo $0,4 \mathrm{~m}$ antes do início e término da escada ou da rampa, sem interferir com a área de circulação ou prejudicar a vazão, conforme recomendado. Percebe-se, portanto, a necessidade de readequação para possibilitar a locomoção das pessoas portadoras de deficiência.

O corrimão instalado de ambos os lados, com prolongamento de pelo menos $30 \mathrm{~cm}$ no início e término da escada, é considerado fator de apoio para as pessoas. As pessoas com deficiência motora, e, em particular as que dependem de muletas, têm sua liberdade de caminhar preservada quando empunham o corrimão e transferem parte do peso para o apoio fixo. Este procedimento tem de ser executado pelo membro contra lateral ao que apresenta a deficiência. Por este motivo, quando localizado apenas unilateralmente, não atende a uma parcela das pessoas. Em nenhuma das unidades hospitalares avaliadas o corrimão prolonga-se por pelo menos $0,30 \mathrm{~m}$ do início e final da escada.

Consoante determinado, as portas do tipo vai-e-vem devem ter visor com largura mínima de $0,20 \mathrm{~m}$, com a face inferior situada entre $0,40 \mathrm{~m}$ e $0,90 \mathrm{~m}$ do piso e face superior no mínimo a $1,50 \mathrm{~m}$. O visor deve estar localizado entre o eixo vertical central da porta e lado oposto às dobradiças. Em portas de correr, os trilhos ou guias inferiores não devem se projetar acima da superfície do piso.

Em relação ao piso, deve ter superfície regular, firme, estável e antiderrapante sob qualquer condição climática. As áreas de circulação devem ser dimensionadas, assegurando-se uma faixa de circulação livre de obstáculos. Sempre que houver mudança de inclinação ou de plano, o piso deve ter tratamento diferenciado para facilitar a identificação destas transições ${ }^{10}$. Em cinco escadas fomos encontrados o piso ideal. Isto corresponde a $38 \%$ das exigências preconizadas pela legislação. Mas o mais comum são escadas com pisos convencionais. Apenas em um dos hospitais a escada possui patamar de $1,20 \mathrm{~m}$ a cada mudança de direção ou em desnível superior a $0,35 \mathrm{~m}$. A presença desse item de segurança possibilita as manobras necessárias à locomoção de acesso aos próximos degraus.

Conforme se observa, dos doze itens avaliados quanto ao piso das escadas, apenas quatro atendem a $100 \%$ das exigências legais e propiciam segurança às pessoas que transitam por elas, quer sejam pessoas deficientes ou não, pois o preconizado pela legislação visa preservar a integridade física dos usuários de forma geral. Como adverte a literatura, a cidade e seus equipamentos urbanos produzem a exclusão social quando não facilitam a mobilidade no ir e vir, e impedem o real sentido da cidadania ${ }^{(15)}$.

Isso leva a refletir sobre a condição do hospital. De acordo com a complexidade, a estrutura organizacional e arquitetônica pode ser considerada verdadeira cidade, até mesmo pelo contingente de pessoas a circular nestas instituições. Conforme mostra a análise das condições das escadas, nos três hospitais onde elas estão presentes, todas as exigências legais referentes às dimensões dos degraus são atendidas. Já a presença de corrimões de materiais rígidos e firmemente fixados ocorreu em apenas $40 \%$ delas, e há escadas sem corrimão de ambos os lados. Portanto, este item não atende às exigências preconizadas pela NBR 9050 .

Nos mobiliários disponíveis nas unidades em estudo dos quatro hospitais, as barreiras ou dificuldades são mais evidentes do que as facilidades. Este tipo de situação gera medo do futuro no deficiente físico, pois ressalta a iminência da sua exclusão e inibe seu esforço na busca do reconhecimento social ${ }^{(16)}$.

Como observado, as dificuldades de acesso sobressaem nos balcões protegidos por grades nas áreas de recepção de pacientes, com vistas a preservar a integridade física dos funcionários contra violências físicas advindas de clientes 
usuários de substâncias como álcool ou drogas ou ainda de pessoas agressivas, ansiosas por solucionar seus problemas rapidamente e de forma prioritária.

Ainda segundo recomendado pelas normas, os balcões de atendimento devem permitir aproximação frontal pelo menos para uma cadeira de rodas, e ser instalado a $0,80 \mathrm{~m}$ do piso, com altura livre mínima de $0,70 \mathrm{~m}$. Quanto aos telefones, devem atender aos requisitos de acessibilidade e permitir sua utilização nos casos de deficiência ambulatória e sensorial auditiva parcial. É preciso haver no mínimo 5\% dos telefones instalados pela concessionária, por tipo, ou seja, local e DDD. Assim, sempre que houver um conjunto de telefones de uso público, pelo menos um dele deve atender a estas exigências legais.

Em relação aos bebedouros, devem permitir a aproximação da cadeira de rodas e ser acessível à bacia. As bicas e os comandos devem estar a uma altura de $0,80 \mathrm{~m}$ do piso. Os dispositivos de acionamento devem permitir a operação manual e ser do tipo alavanca. É facultativo o uso de barras para apoio de pessoas com mobilidade reduzida nas pernas, para evitar assim que se apóiem diretamente nos bebedouros. Os bancos devem ser providos de encosto, ter profundidade de $0,45 \mathrm{~m}$ e ser instalados a uma altura de $0,46 \mathrm{~m}$ do piso $^{(10)}$. Ainda de acordo com o observado, em apenas duas unidades de um dos hospitais em estudo foram identificadas botoeiras destinadas a atendimento de emergência, ou seja, ambas estão de acordo com a lei, segundo a qual devem ficar a uma altura entre $0,80 \mathrm{~m}$ e $1,20 \mathrm{~m}$ do piso.

No intuito de promover a inclusão das pessoas portadoras de limitações, os mobiliários dos hospitais devem ser adequados a elas. Para isso é essencial universalizar o direito destas pessoas. Nesse sentido, os países mais avançados devem servir de parâmetro para os menos avançados. Cabe ao Estado e à sociedade criar condições para as pessoas portadoras de deficiência terem igualdade de direito.

Também em relação ao observado, a padronização de bancos de uso público não corresponde ao preconizado pela legislação. De acordo com o recomendado, eles devem ser providos de encosto, ter profundidade de $0,45 \mathrm{~m}$ e estar instalados a uma altura de $0,46 \mathrm{~m}$ do piso. Além disso, deve ser reservado um espaço frontal ao assento de $60 \mathrm{~m}$, com vistas a favorecer a circulação da pessoa com dificuldades de mobilidade física. No referente aos espaços livres entre os assentos ambulatoriais com espaço frontal de $0,6 \mathrm{~m}$, treze unidades $(32 \%)$ respeitaram estas exigências. Tal dado foi incompatível com o padrão de assentos ambulatoriais de uso público. Percebe-se, portanto, a necessidade de mais esclarecimentos e conscientização quanto à inclusão de todas as pessoas, independentemente da sua condição física.
Em relação aos bebedouros, 39 não atendem às medidas preconizadas de $0,80 \mathrm{~m}$ do piso. Por se tratar de suportes para garrafões, estão a uma altura de $0,45 \mathrm{~m}$, ou seja, são acessíveis às pessoas de um modo geral. Neste caso, as dificuldades não são ocasionadas pela altura dos equipamentos, mas por outros fatores como a inexistência de porta-copo e de copos. Esses impasses podem ser considerados de fácil resolução, e talvez isso ocorra por não percebermos os problemas quando eles não nos atingem. Dos bebedouros, um atende às medidas preconizadas por lei, mas a inacessibilidade ocorre em razão da estrutura apresentada, a qual gera dificuldades de aproximação das pessoas, até mesmo das convencionalmente normais.

Dos telefones encontrados, apenas um está instalado à altura de $0,80 \mathrm{~m}$ do piso. No entanto, este só é considerado de uso público por ocasião de eventos científicos, por se localizar em um dos auditórios. Os demais estão em altura que impossibilita o acesso das pessoas portadoras de deficiência física, pois não oferecem área de apoio nem acesso a cadeira de rodas. Além disso, pessoas de baixa estatura não têm como usar estes equipamentos, o que inviabiliza o processo de inclusão de todos os cidadãos a despeito das diferenças de cada um.

Esse processo de inclusão é complexo, que envolve tanto os aparatos físicos quanto os sociais. Além de todas as barreiras físicas encontradas, ressalta-se a existência do despreparo do profissional de saúde para atuar com essa clientela ${ }^{(17)}$, relacionado intrinsecamente com a abordagem acadêmica especificamente na enfermagem ${ }^{(18)}$.

\section{CONCLUSÕES}

Como evidenciado, os resultados do estudo confirmam barreiras arquitetônicas no interior dos hospitais de Sobral, com conseqüente comprometimento do deslocamento de pessoas portadoras de deficiência física. Estas barreiras são constituídas por escadas, rampas e inadequação dos mobiliários e equipamentos que não atendem à legislação.

Cabe, portanto, à administração dos hospitais estarem atenta à legislação e cumpri-la. Para isto, é preciso assessorar-se de profissionais devidamente capacitados na área, incluídos aí o arquiteto e o engenheiro. A equipe de saúde também deve conhecer os princípios da acessibilidade para preservar aqueles já incorporados à arquitetura hospitalar e solicitar orientação adequada quando identificar barreiras no ambiente. Defende-se que a implantação e manutenção de ambientes acessíveis perpassam pela tomada de consciência do real significado de ambiente acessível. E que este vai além das barreiras arquitetônicas, pois depende da atitude inclusiva. 


\section{REFERÊNCIAS}

1. Godoy A, Nunes CP, Reis DA, Hatem DS, Lorentz LN, Ferreira MJ. Cartilha da inclusão dos direitos da pessoa com deficiência. Belo Horizonte: PUC/MG; 2000.

2. Ceará. Secretaria da Saúde do Estado. Qualidade hospitalar: instrumento de avaliação. Fortaleza; 2001

3. Brasil. Lei n. 10.098, de 19 de dezembro de 2000. Estabelece normas gerais e critérios básicos para promoção de acessibilidade das pessoas portadoras de deficiência ou com mobilidade reduzida e dá outras providências [legislação na Internet]. Brasília; 2000. [citado 2005 jan. 6]. Disponível em: http:// www.planalto.gov.br/ccivil/LEIS/L10098.htm

4. Brasil. Ministério da Justiça. Lei n. 7.853, de 24 de outubro de 1989. Dispõe sobre o apoio às pessoas portadoras de deficiência, sua integração social, e sobre a Coordenadoria Nacional para Interação da Pessoa Portadora de Deficiência (CORDE) [legislação na Internet]. Brasília; 1989. [citado 2003 out. 11]. Disponível em: http://www.mj.gov.br/sedh/ct/corde/dpdh/corde/ lei7853.asp

5. Leopardi MT, Beck CLC, Nietsche EA, Gonzales RMB. Metodologia da pesquisa na saúde. Santa Maria: Paloti; 2001.

6. Dias MSA. Cuidado especial de enfermagem na pessoa portadora de insuficiência renal crônica. Fortaleza: Ed. UFC; 2001.

7. Portela MC, Lima SML, Barbosa PR, Vasconcellos MM, Ugá MAD, Gerschman S. Caracterização assistencial de hospitais filantrópicos no Brasil. Rev Saúde Pública [periódico na Internet]. 2004 [citado 2006 fev. 17];38(6): [cerca de 7 p.]. Disponível em: http://www.scielo.br/pdf/rsp/v38n6/09.pdf

8. Aragão AEA. Acessibilidade da pessoa portadora de deficiência física aos serviços hospitalares: avaliação das barreiras arquitetônicas [dissertação]. Fortaleza: Faculdade de Enfermagem, Universidade Federal do Ceará; 2004.

9. Pagliuca LMF, França ISX, Moura ERF, Caetano JA, Macedo KNF, Vasconcelos LR, et al. Acessibilidade da pessoa portadora de deficiência física e/ou sensorial aos serviços de saúde: estudo das condições físicas e de comunicação [relatório de pesquisa]. Fortaleza: Universidade Federal do Ceará; 2004.
10. Associação Brasileira de Normas Técnicas (ABNT). NBR 9050: Acessibilidade de pessoas portadoras de deficiências e edificações, espaço, mobiliário e equipamento urbano. Rio de Janeiro; 1985.

11. Conselho Nacional de Saúde. Resolução n. 196, de 10 de outubro de 1996. Dispõe sobre diretrizes e normas regulamentadoras de pesquisas envolvendo seres humanos. Bioética. 1996;4(2 Supl):15-25.

12. Aragão AEA, Marcelino MF, Ximenes Neto FRG. Irmandade da Santa Casa de Misericórdia de Sobral: breve histórico e perfil assistencial. In: Irmandade da Santa Casa de Misericórdia de Sobral. Diretrizes do serviço de enfermagem. Sobral (CE); 2002. p. 15-7.

13. Passos NMG. O processo de acreditação: impacto nos serviços de enfermagem. Fortaleza: Pouchain; 2002.

14. Pianucci A. Saber cuidar: procedimentos básicos em enfermagem. $4^{a}$ ed. São Paulo: SENAC; 2004.

15. França IP. A incompatibilização da cidade para cidadãos deficientes da locomoção: uma questão de cidadania [dissertação]. Fortaleza: Faculdade de Enfermagem, Universidade Federal do Ceará; 1995.

16. França ISX. Formas de sociabilidade e instauração da alteridade: vivência das pessoas com necessidades especiais [tese]. Fortaleza: Universidade Federal do Ceará; 2004.

17. Macêdo KNF, Pagliuca LMF. Características da comunicação interpessoal entre profissionais de saúde e deficientes visuais. Rev Paul Enferm. 2004;23(3/4):221-6.

18. França ISX, Pagliuca LMF, Sousa RA. Discurso político-acadêmico e integração das pessoas com deficiência: das aparências aos sentidos. Rev Esc Enferm USP. 2003;37(4):24-33. 